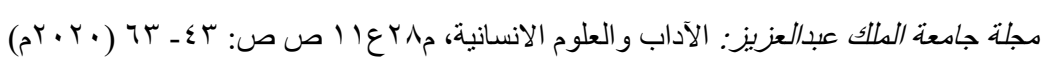

$$
\begin{aligned}
& \text { DOI:10.4197/Art.28-11.3 }
\end{aligned}
$$

\title{
مستوى الشراكة المجتمعية بين جامعة نجران ومنطقة نجران من وجهة نظر اعضاء هيئة التدريس في الجامعة
}

\author{
د. فؤاد شبيب الخصاونة \\ أستاذ الإدارة تربوية المساعد

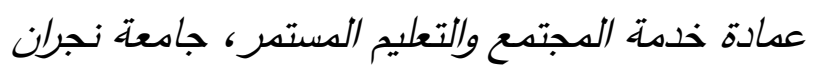

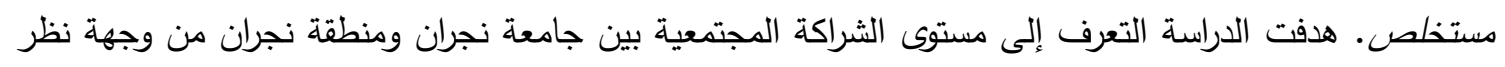

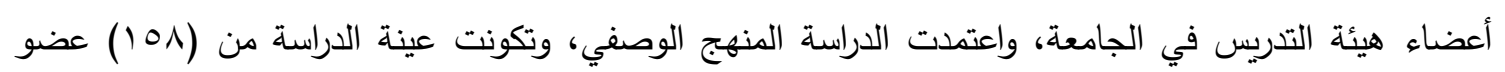

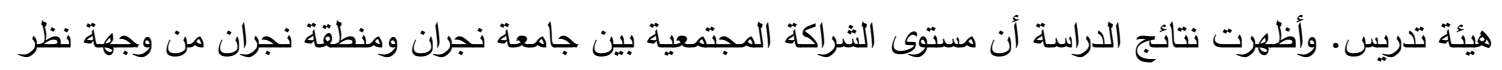

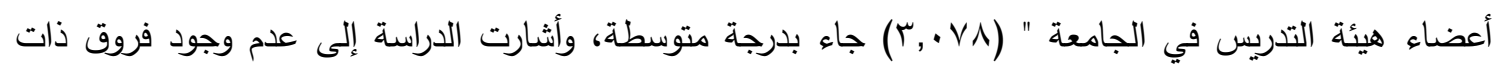

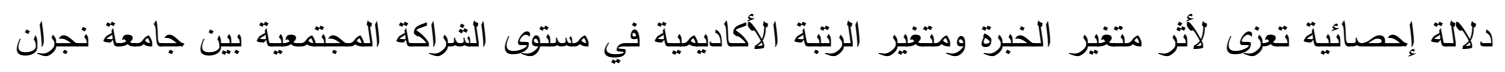

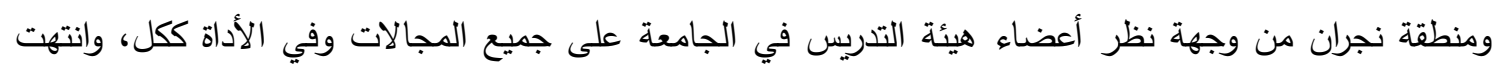

$$
\text { الدراسة بعدة توصيات. }
$$

الكلمات المفتاحية: الثراكة المجتمعية، هنطقة نجران، جامعة نجران، أعضاء هيئة التدريس، السعودية.

والمجتمع تتدافع فيها الرؤى والقيم لتحقيق التكيف

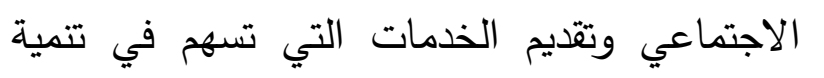

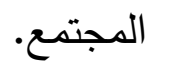
أحدثت العولمة تغييرات كبيرة في العالم في جميع المجالات، ويجب أن تكون الجامعات في طليعة

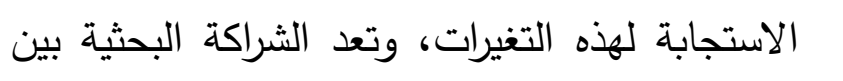

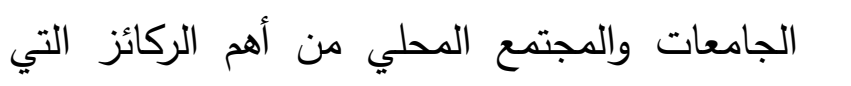

\section{المقدمة}

تعد الجامعة مؤسسة تربوية تنموية تعمل على تقديم

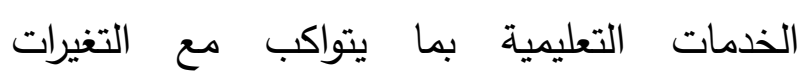

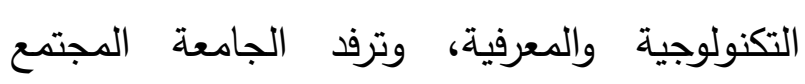
بالبحث العلمي والخبرات والمعارف التي من شأنها

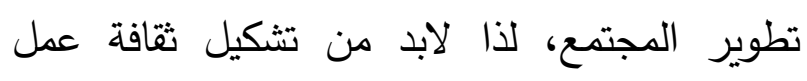

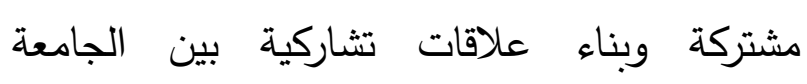




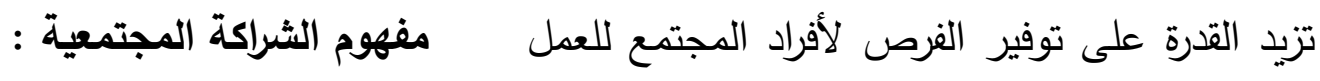

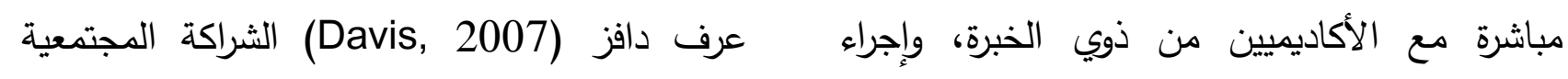
بأنها: علاقة تعاون إرادية بين طرفين أو أكثر تجمع

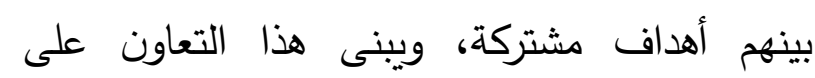
اتفاقيات مبرمة بين الأطراف، تحدد فيها أهداف هداف

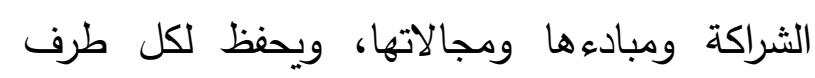

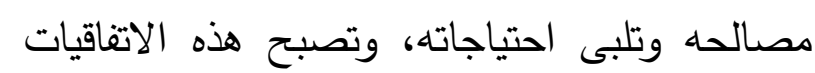
مسؤولية ملزمة لأطرافها. والشراكة المجتمعية هي جهود تقوم بها الجامعات لاطراتهات في التعاون مع مؤسسات المجتمع والبيئة المحيطة بالجامعة، وبالعملية التعليمية لبناء علاقات مشتركة تبادلية من شأنها الارتقاء بمستوى التعليم، وتفعيل

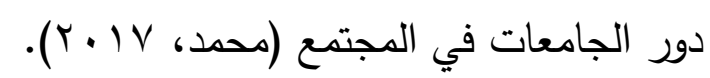
أهداف الثراكة المجتمعية:

تهدف الشراكة المجتمعية القائمة بين الجامعات

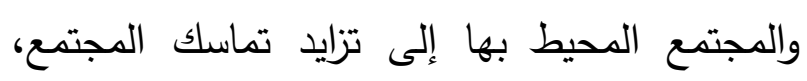
وزيادة قدرتهم وإكسابهم مهارات جديدة لتفعيل دور الإنسان في تتمية المجتمع وتطويزه، والمساهمة في وادي

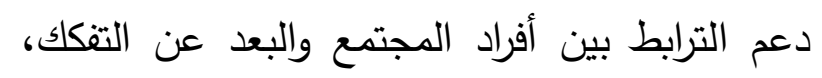

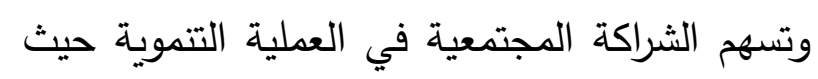

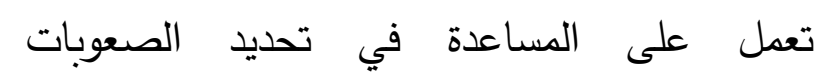
والمشكلات التي تواجه حياة السكان مما يسهل في رسم السياسات لمعالجة المشكلات والصعوبات وزيادة أوجه التعاون والتتسيق بين مختلف الأطراف

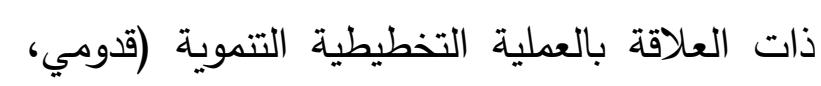
. (r... 1

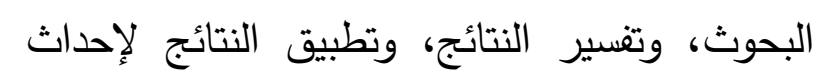
تغيير إيجابي في مجتمعاتهم. كما يتضمن نهاج وتهير الشراكة المجتمعية أساليب بحث جديدة ومبتكرة لتلبية احتياجات المجتمع وتحقيق نتائج مهمة ومفيدة للمجتمع ككل، فهي تمثل حركة مثيرة للمشاركة

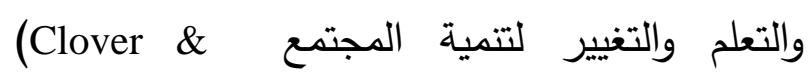
.McGregor, 2008).

وتسهم الثراكة المجتمعية بين المؤسسات التعليمية

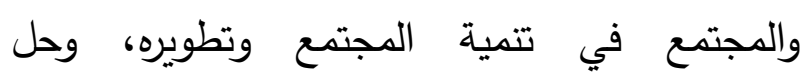
المشكلات التي يعاني منها المجتمع، نظراً لإمكانية

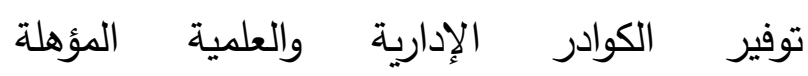
والمتخصصة التي تساعد في تحقيق النهضة الحقيقية للمجتمع، وتعد الشراكة المجتمعية ركيزة أساسية في دعم وتحسين التعليم وزيادة فاعلية المؤسسات التعليمية وتمكينها من تحقيق أهدافها

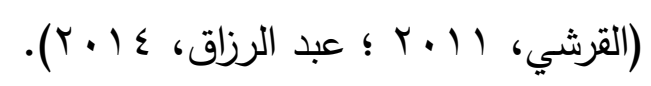

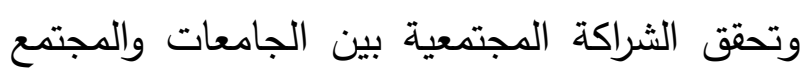

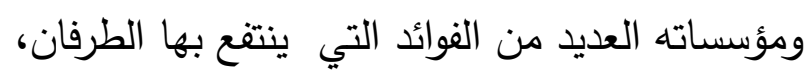
فالشراكة المجتمعية توفر للجامعة الموارد المالية الإضافية لتمويل مشروعاتها، وتسويق خدماتها، وربط برامجها وأبحاثها باحتياجات المجتمع، ويستيد

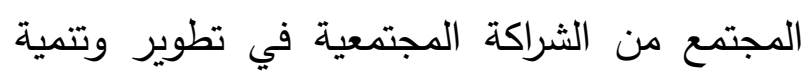
المجتمع، والحصول على المعرفة المتطورة التي لتحئي

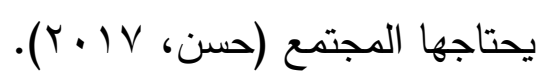


والمجتمع والمؤسسات المجتمعية التي تزيد من فاعلية الثراكة من خلال التسيق والتكامل بين الطرفين للوصول إلى أبحاث ودراسات علمية منقحة تساعد في تتمية المجتمع في جميع المجالات.

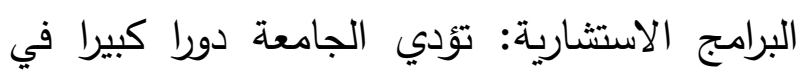

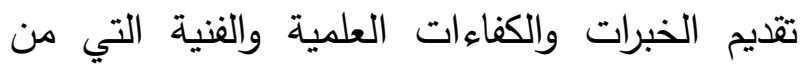
شأنها أن تقدم مستوى عالياً من الخبرات في جميع المعارف التي تقيد المجتمع من خلال إنشاء مكاتب

$$
\text { استشارية في الجامعات. }
$$

الإثراف: يمكن للجامعات أن تعقد علاقات وشراكات بينها وبين مؤسسات المجتمع المختلفة للإثراف على لعدي المناهج الدراسية، والبرامج التي تقدمها للاستفادة من لئن الخبرات والإمكانات البحثية في الجامعات وتطوير

$$
\text { مؤسسات المجتمع وتتميتها. }
$$

التدريب والتعليم: تقوم الجامعات على إتاحة الفرصة للتعليم لجميع أفراد المجتمع، وهذا يساعد في تتمية

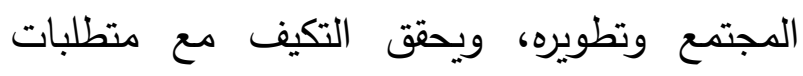

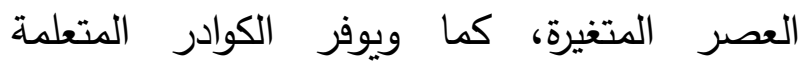
والمدربة. - مان. الابتكارات العلمية: توفر الجامعات الاحتياجات المادية والتسهيلات لإجراء ابتكارات جديدة والحصول على براءات اختراع تفيد المجتمع، وتعود على لإنى الجامعة بالنفع المادي حيث أن من حقها الحصول على العوائد المالية لهذه الابتكارات.

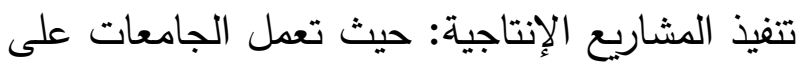
تتفيذ المشاريع الإنتاجية التي يقوم بها أعضاء هيئة
متطلبات الثراكة المجتمعية حدد زيدية (Y (Y. r) متطلبات الثراكة المجتمعية وهي تتمثل في شعور كل فرد من أفراد المجتمع

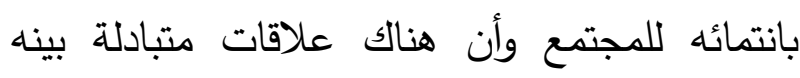
وبين كل فرد فيه، ووجود تعاون طوعي بين أفراد

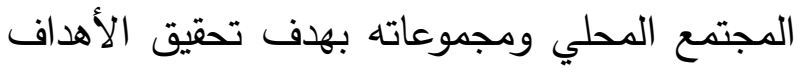

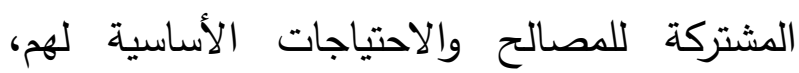
ووجود معارف وخبرات محلية تمكن من الاعتماد على الذات، ووجود مؤسسات وتتظيمات مجتمعية فعالة وقادرة على تعبئة طاقات أفراد المجتمع المحلي وتلي وتحقيق أهدافهم، ووجود نظم لا مركزية وعلاقات

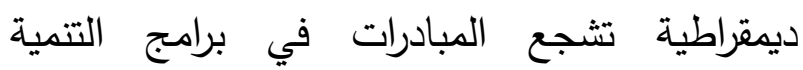
المجتمعية بكافة مراحلها.

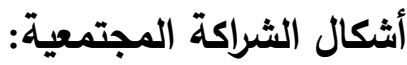
للشراكة المجتمعية في الجامعات العديد من الأشكال

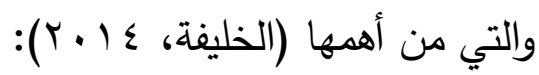

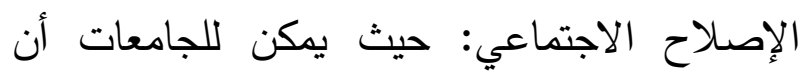
تؤدي دوراً كبيراً في الإصلاعي الإحلاء الاجتماعي كونها تستقطب عدداً كبيراً من أفراد المجتمع، حيث يمكنها أن تشارك في تقويم البرامج السياسية والاقتصادية والاجتماعية للمجتمع. والبحوث والدراسات: تقدم الجامعات العديد من البحوث والدراسات التي تهتم بتوليد وإنتاج المعرفة

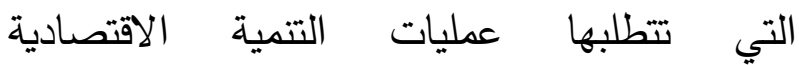

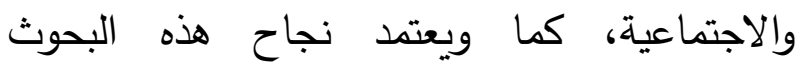
الدراسات على قوة الشراكة المجتمعية بين الجامعات 
التدريس والطلبة بالتعاون مع مؤسسات المجتمع على المدى الطويل. وتم البدء في تأملات استرجاعية كتقييم ذاتي غير رسمي مصمم للتركيز سواء الحكومية أو الخاصة. على عمليات تنفيذ الدورة، وتطوير الشراكة، كمنهج

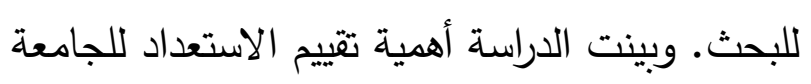

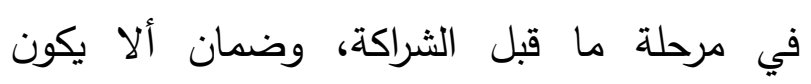
الأكاديميون ومؤسساتهم راغبين فقط، كما يمكنهم في المشاركة في شراكات بحثية مجتمعية فعالة كذلك. Baker, \& ) وقام باكير ووايلكيرسون وبيرنان (Wilkerson, \& Bernan, 2012 إلى تلخيص الجوانب الهيكلية والوظيفية للشراكات التي تم تحديدها على أنها ذات تأثير جوهري على هذه المبادرات. وشمل التتييم أساليب مختلطة النوعية ( كالمقابلات الرئيسية للمخبر و مجموعات التركيز ) والطرق الكمية (مثل المسح و التتبع عبر الإنترنت).

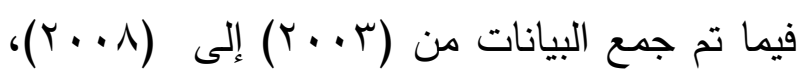
وتحليلها بشكل منهجي لتحديد العوامل المؤثرة في

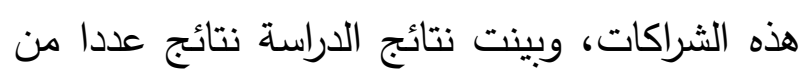
العوامل الهيكلية، والوظيفية، التي كانت مهمة لنجاح الشراكات المجتمعية، بما في ذلك الشركاء متعددو

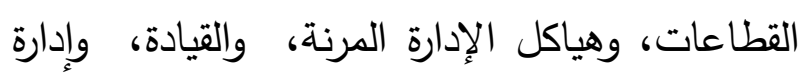

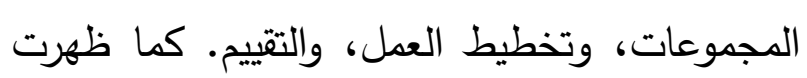
ثلاثة أنواع من نماذج الثراكة - النفعية، والوكالة

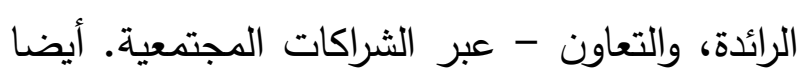
أفادت معظم الشراكات إلى ضرورة دراسة التحديات التي تواجه إشراك أفراد المجتمع، وضمان التوزيع

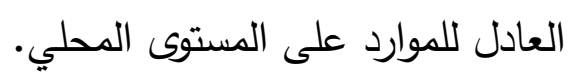

أجريت العديد من الدراسات المتعلقة بالثراكة Buys \& ) المجتمعية، ومنها: دراسة بويز وبورسنال

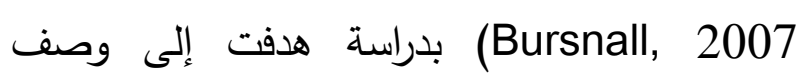
ودراسة تجربة سبعة أكاديميين بنجاح في إقامة شراكات مجتمعية. وفحص العمليات التي يتم من فن فئن خلالها تأسيس الشراكات وتتفيذها باستخدام إطار

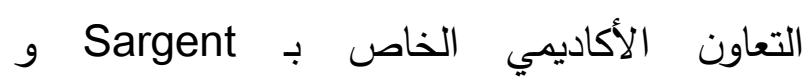
Waters كما يستكشف الفوائد المتصورة للشراكات

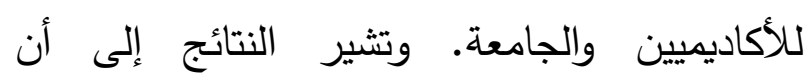
مجموعة من الفوائد تبرز عن مثل هذه الشراكات من وندير

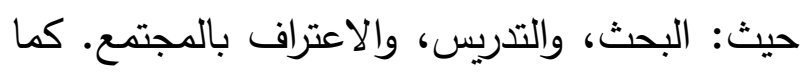

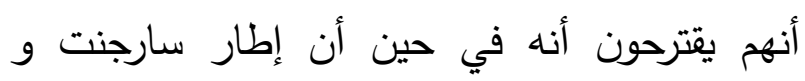

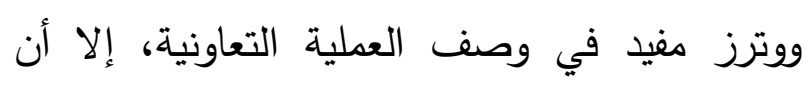

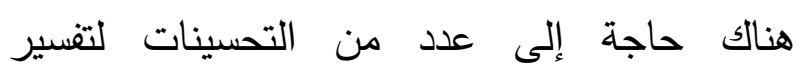
الشراكات بين الجامعة والمجتمع. Curwood \& ) وقام الباحثون كيروود ومونقر وفارار دالى (Munger, \& Farrar, 2011 دراسة تفكير الطلاب، وأعضاء هيئة التدريس،

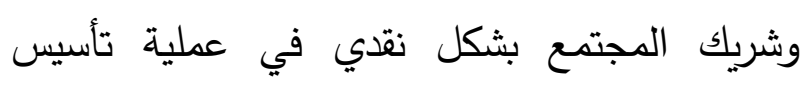

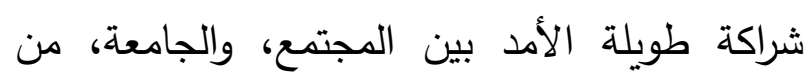
خلال دمج مكون تعلم خدمة المجتمع في برنامج

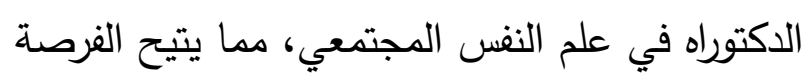

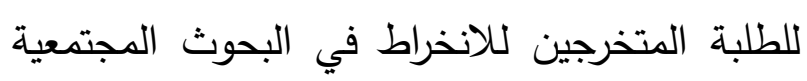


البيانات إحصائياً وتوصلت الدراسة إلى أن دور إدارة

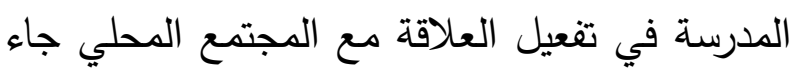
بدرجة متوسطة.

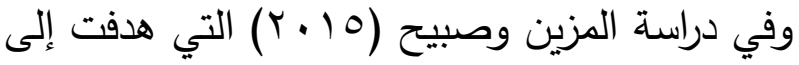
الكثف عن معوقات تفعيل الشراكة المجتمعية في الجامعات الفلسطينية بمحافظات غزة، وسبل الحد منها، ولتحقيق ذلك استخدم الباحثان المنهج الوصفي التحليلي، طبقت على عينة عشوائية من أعضاء

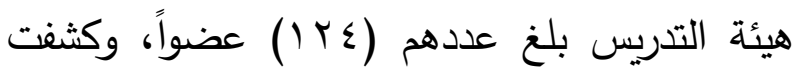
الدراسة عن وجود مجموعة من المعوقات تحد من الثراكة المجتمعية للجامعات الفلسطينية: معوقات بشرية حيث انشغال أعضاء هيئة التدريس بمهام

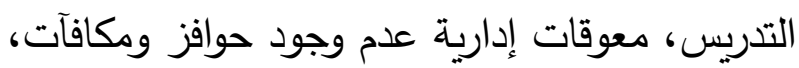
ثم المعوقات الثقافية كالفجوة المعلوماتية بين الجامعات الفلسطينية ومؤسسات الشراكة، وقدمت الدراسة مجموعة من السبل للحد من المعوقات أهمها: التخطيط الجيد للشراكة، توفير ميزانية خاصة

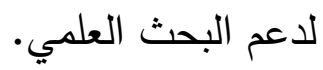
وقام الباحثون بروستر وباسني وراميسير ووايز Brewster, \& Pisani, \& Ramseyer, r. 1 7) \&Wise,

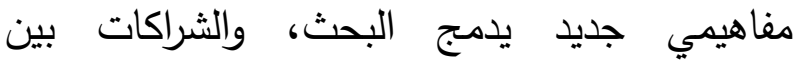
الجامعات والمجتمع، ونهج الفريق الجامعي المبتكر لمعالجة المشكلات الاجتماعية بشكل أكثر فعالية

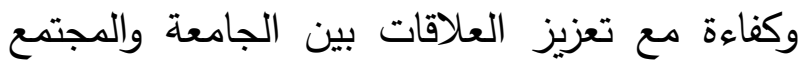
وتوفير خبرات تعليمية قيمة للطلاب. فيما تصف لتفريز

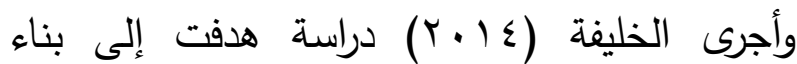
صيغة مقترحة لتفعيل الثراكة المجتمعية لجامعة الإمام محمد بن سعود الإسلامية كنموذج للجامعات السعودية في ضوء فلسفة الجامعة المنتجة، وذلك من خلال تحديد الإطار الفلسفي للجامعة المنتجة

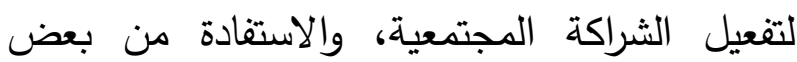
التجارب العالمية لتفعيل الشراكة المجتمعية للجامعات في ضوء فلسفة الجامعة المنتجة. والتعرف إلى وجهة نظر أعضاء هيئة التدريس في الجامعة على أهمية تطبيق الصيغة المقترحة لتفعيل الشراكة المجتمعية للجامعة في ضوء فلسفة الجامعة المنتجة

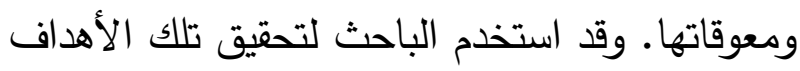
المنهج الوصفي المسحي. وقد توصلت الدراسة لصيغة مقترحة لتفعيل الشراكة المجتمعية للجامعة في ضوء فلسفة الجامعة المنتجة؛ تقوم على تحديد الأسس والمنطلقات للصيغة المقترحة، وأهدافها، وخطوات بنائها، والدواعي والأسباب لبنائها، ومتطلبات تفعيل الشراكة المجتمعية للجامعة، والآليات المقترحة لتفعيل الشراكة المجتمعية للجامعة. وقام النوح (10 ب ب) بدراسة هدفت التعرف إلى دور إدارة المدرسة في تفعيل الثراكة مع المجتمع المحلي كما يراها مديرو المدارس الثانوية والمتوسطة بمدينة الرياض، واستخدم الباحث المنهج الوصفي معتمداً

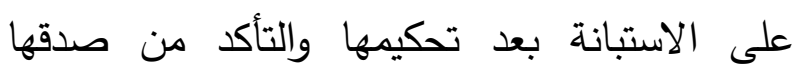

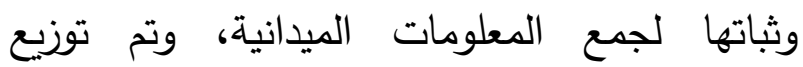
الاستبانة على أفراد الدراسة وجمعها ومعالجة 
الورقة الأساس المنطقي والمكونات الأساسية الحسابية لاستجابة أعضاء هيئة التدريس لدرجة

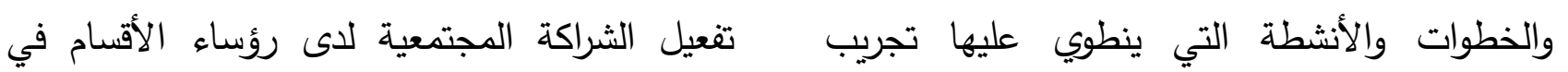
النموذج المفاهيمي للمشاركة الجامعية - المجتمعية. الجامعات الخاصة جاءت بـات بدرجة مرتفعة.

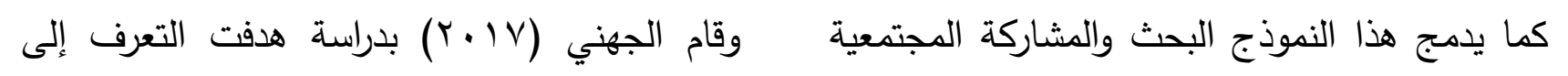
والتطوير الجامعي والتعليم جنبا إلى جنب مع التقييم دور إدارة الثراكة المجتمعية بإمارة منطقة المدينة

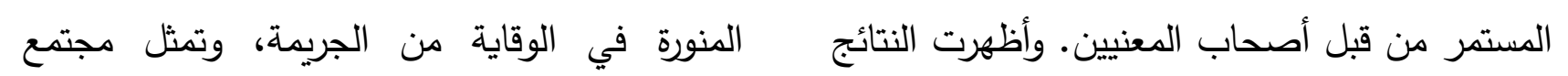

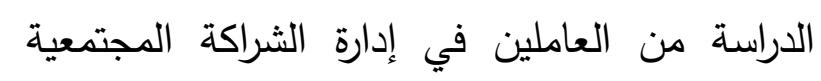
بإمارة منطقة المدينة المنورة وعدد من رجال الأمن

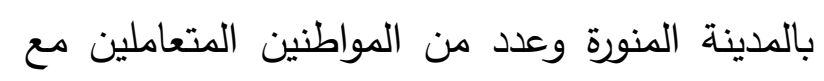
إدارة الشراكة المجتمعية بإمارة منطقة المدينة المنورة

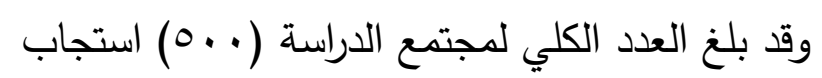
منهم عدد (Y^T) وهو حجم العينة، وأظهرت النتائج أن المشكلات الأمنية التي يمكن وهو لإدارات الشراكة المجتمعية أن تسهم في الحيلولة دون وقوعها (الوقاية منها التي حظيت بدرجة موافقة عالية من أفراد العينة كالتالي تعاطي المواد المخدرة، الإتجار بالمخدرات،

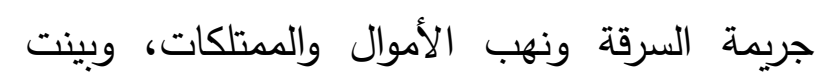
النتائج أن المعوقات التي قد تحول دون قيام إدارات

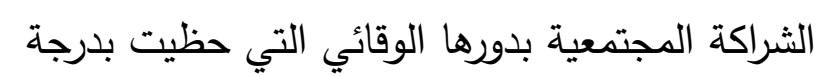

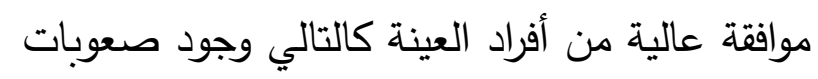
إدارية وتتظيمية تعيق عملية الشراكة المجتمعية.

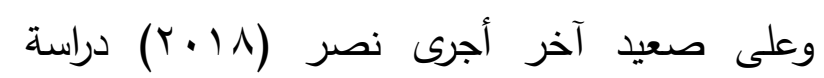
هدفت إلى تفعيل الثراكة المجتمعية بجامعة تبوك الهري

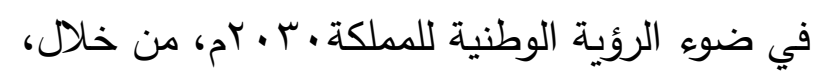

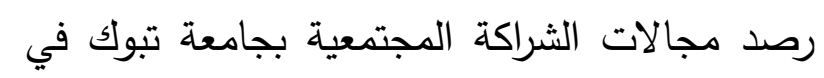
ضوء الرؤية الوطنية للمملكة العربية السعودية

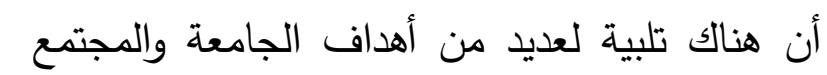

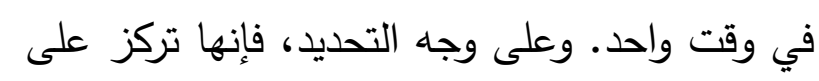

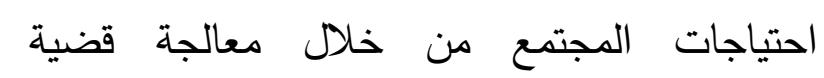
اجتماعية متفق عليها بشكل متبادل، وتبني وتعزز

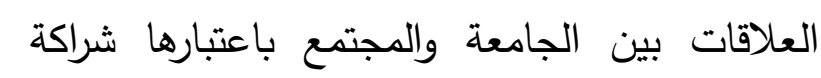

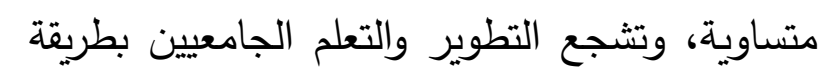

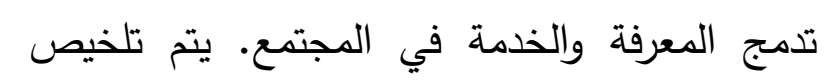
النتائج المحددة في كل مجال.

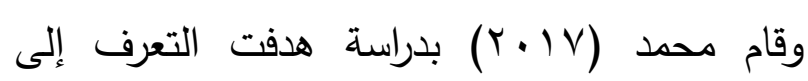
درجة تفعيل الشراكة المجتمعية لدى رؤساء الأقسام

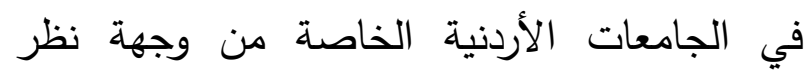
أعضاء هيئة التدريس، وتكونت عينة الدراسة من الأنس

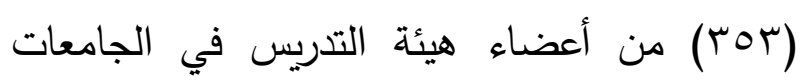

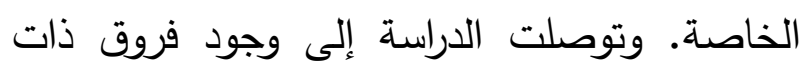
دلالة إحصائية في درجة تفعيل الشراكة المجتمعية لاى رؤساء الأقسام في الجامعات الخاصة من وجهة دلهة نظر أعضاء هيئة التدريس، تبعا لـتغير الجنس

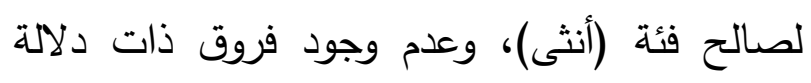

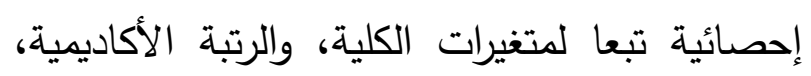

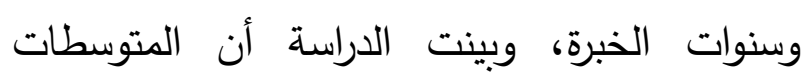


لنوع الكمية لصالح الكميات النظريـة، وللجنس ل ل 1. 1الح الذكور ، ولسنوات الخبرة لصالح أكثر من سنوات. ولا توجد فروق دالة إحصائياً بين متوسطات استجابة أعضاء هيئة التدريس حول واقع الثراكة المجتمعية و درجة ممارسة مجالاتها تعزى للدرجة العلمية، وسنوات الخبرة. التعقيب على الدراسات السابقة: هدفت الدراسات السابقة التعرف إلى درجة تفعيل الشراكة المجتمعية لدى رؤساء الأقسام في الجامعات الأردنية مثل دراسة (محمد، V V • إ)، والتعرف إلى دور إدارة الشراكة المجتمعية بإمارة منطقة المدينة المنورة في الوقاية من الجريمة مثل دراسة (الجهني،

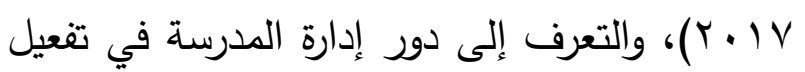
الشراكة مع المجتمع المحلي مثل دراسة (النوح، 1. 1. المجتمعية لجامعة الإمام محمد بن سعود الإسلامية كنموذج للجامعات السعودية في ضوء فلسفة الجامعة المنتجة مثل دراسة (الخليفة، ؟ ا • ب). بينما هدفت الدراسات الأجنبية إلى وصف نموذج مفاهيمي جديد يدمج البحث، والشراكات بين Brewster et ) الجامعات والمجتمع مثل دراسة (al., 2016 )، وتلخيص الجوانب الهيكلية والوظيفية للشراكات التي تم تحديدها على أنها ذات تأثير جوهري مثل دراسة (Baker et al., 2012)، ودراسة تفكير الطلاب، وأعضاء هيئة التدري، وشريك المجتمع بشكل نقدي في عملية تأسيس
• . • r.م، الوقوف على أهم متطلبات تفعيل الشراكة المجتمعية بجامعة تبوك في ضوء الرؤية الوطنية للمملكة العربية السعودية ، r • rم، واستخدم البحث المنهج الوصفي لملائمته لموضوع الدراسة من حيث التعرف على مجالات الشراكة ومتطلبات تفعيلها

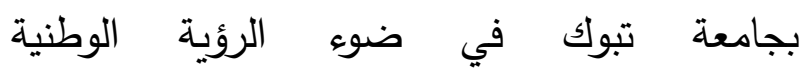
للمملكة .r • rم، واستخدمت الاستبانة كأداة لتطبيق الدراسة الميدانية على عينة ممثلة من أعضاء هيئة التدريس بجامعة تبوك وفقاً لمتغيرات الرتبة العلمية، والجنس، وسنوات الخبرة، وكان من ابرز نتائج البحث جاءت درجة الأهمية لإجمالي محور مجالات الشراكة المجتمعية بجامعة تبوك كبيرة جداً، وجاءت درجة الأهمية لإجمالي محور متطلبات تفعيل الشراكة المجتمعية بجامعة تبوك كبيرة جداً.

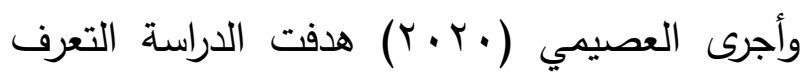
على واقع الثراكة المجتمعية ودرجة مارسة مجالاتها في جامعة الطائف من وجهة نظر أعضاء هيئة التدري، طبقت على عينة عشوائية بلغت ( • (Y) عضواً، وتوصلت الدراسة إلى النتائج التالية: واقع الشراكة المجتمعية في جامعة الطائف جاءت بدرجة متوسطة على الأداة ككل وجاءت المجالات مرتبة تنازلياً: الثقافية، التعليمية، الاقتصادية، الاجتماعية، البحثية. وجميعها بدرجة متوسطة، عدا الثقافية عالية، وتوجد فروق ذات دالة إحصائية بين متوسطات استجابة أعضاء هيئة التدري حول واقع الشراكة المجتمعية و درجة ممارسة مجالاتها تعزى 


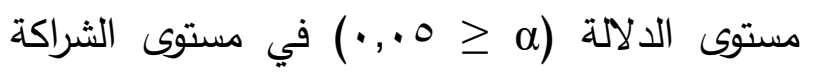

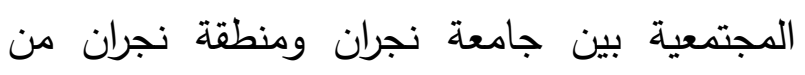
وجهة نظر اعضاء هيئة التدريس في الجامعة تعزى

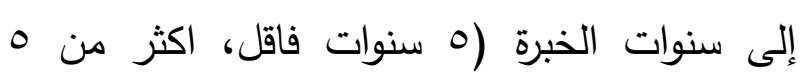
سنوات؟ r - هل توجد فروق ذات دلاله إحصائية عند

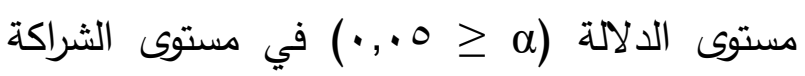
المجتمعية بين جامعة نجران ومنطقة نجران من المن الهن وجهة نظر اعضاء هيئة التدريس في الجامعة تعزى إلى الرتبة الاكاديمية (استاذ مساعد فأقل، استاذ مشارك فأعلى) أهمية الدراسة:

توفر الثراكة المجتمعية للجامعات الأدوات اللازمة

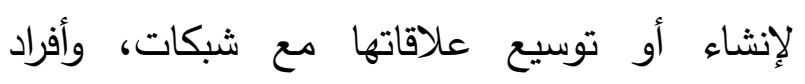
المجتمع المحيط بها، وتساعدها في توضيح الطرق التئاء المختلفة التي قد تظهر بها الشراكات المجتمعية نفسها، والطرق التي يمكن بها تشكيل هذه الشراكات،

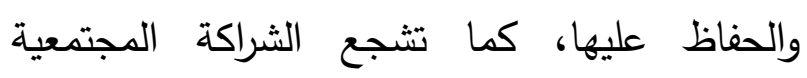
الجامعات على النظر إلى ما وراء الخدمات الحالية التي تقدمها، أو المعتادة لمساعدة أفراد المجتمع في الجي

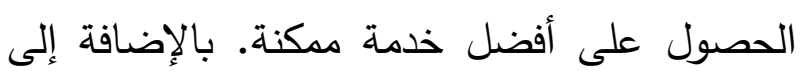
أن الثراكة المجتمعية تشمل كل الترتيبات الرسمية

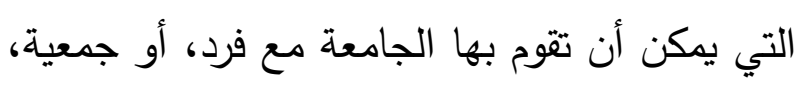

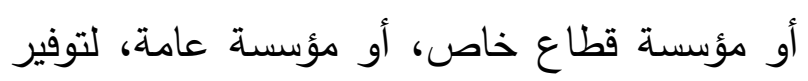

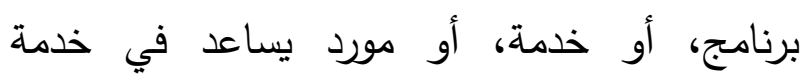
المجتمع.
شراكة طويلة الأمد بين المجتمع، والجامعة، مثل:

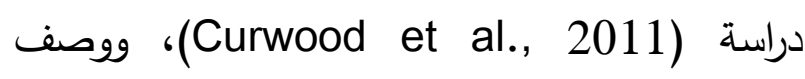
ودراسة تجربة سبعة أكاديميين بنجاح في إقامة Buys \& Bursnall, ) شراكات مجتمعية مثل دراسة فئة فئة . (2007

أما الدراسة الحالية فهدفت التعرف إلى مستوى الثراكة المجتمعية بين جامعة نجران ومنطقة نجران من وجهة نظر أعضاء هيئة التدريس في الجامعة.

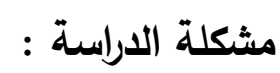

تتطلب التغيرات التي يشهدها وقتنا الحاضر إعادة النظر من قبل الجامعات في طبيعة علاقتها بمجتمعاتها، وذلك نتيجة للتحولات الثاملة والمتلاحقة النظم التعليمية، والتطور المعرفي والعلمي

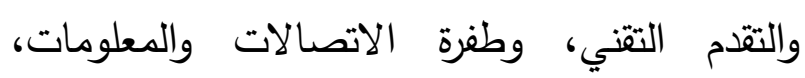

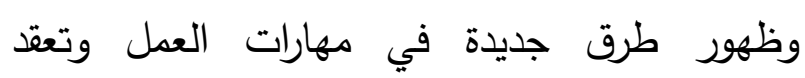
مستوياتها، وزيادة المنافسة بين الجامعات، هذات هذات

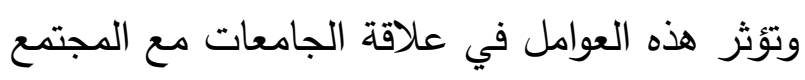

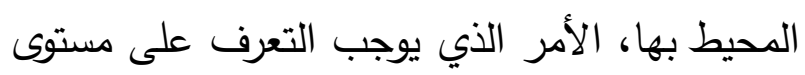
الشراكة المجتمعية بين جامعة نجران ومنطقة نجران الان لهري من وجهة نظر أعضاء هيئة التدريس في الجامعة. أسئلة الاراسة : وجنة نظئ تتمثل أسئلة الدراسة الحالية فيما يلي: 1 - ما مستوى الشراكة المجتمعية بين جامعة نجران

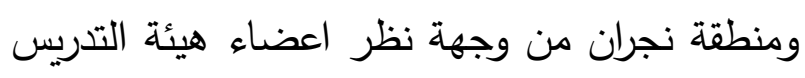

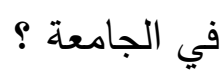
r - هل توجد فروق ذات دلاله إحصائية عند 


$$
\text { في الجامعة. }
$$

مجتمع الاراسة:

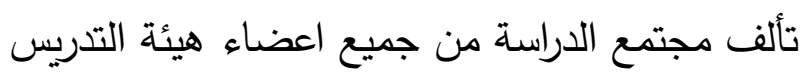

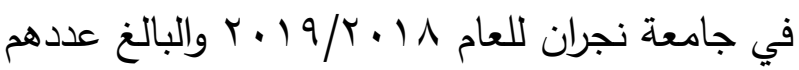

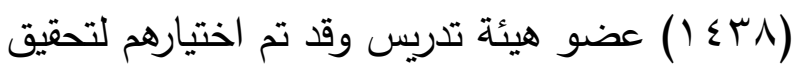
هدف الدراسة الرامي التعرف إلى مستوى الثراكة

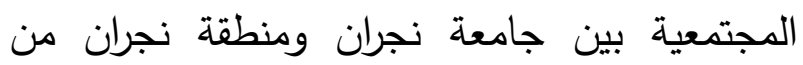
وجهة نظر اعضاء هيئة التدريس في الجامعة عينة الاراسة ووصفها: تكونت عينة الدراسة من (101) عضو هيئة تدريس

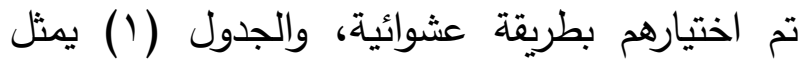
أعداد هؤلاء الأعضاء والنسب المئوية لهذه الأعداد موزعين على الخبرة والرتبة الأكاديمية.

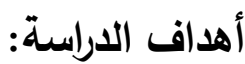
تهدف الدراسة التعرف إلى مستوى الثراكة الدجمعية بين جامعة نجران ومنطقة نجران من وجهة نظر أعضاء هيئة التدريس في الجامعة. محددات الاراسة: تتحدد نتائج هذه الدراسة بالآتي: - ملاعمة الأداة المستخدمة في الدراسة لقياس مالـال

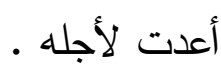
- اقتصار الدراسة على اعضاء هيئة التدريس في

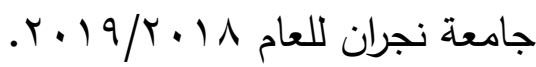
الطريقة والإجراء ات: اعتمدت الدراسة على المنهج الوصفي بهدف التعرف إلى مستوى الشراكة المجتمعية بين جامعة نجران ومنطقة نجران من وجهة نظر أعضاء هيئة التدريس لئن لئن

الجدول (1) توزيع أفراد العينة حسب متغيرات الدارسة

\begin{tabular}{|c|c|c|c|}
\hline النسبة & العدد & الفئات & المتغير \\
\hline$\% \circ v, 0$ & 9) & م سنوات فاقل & \multirow[t]{3}{*}{ الخبرة } \\
\hline$\% \leqslant r, 0$ & TV & أكثر من ه سنوات & \\
\hline$\% 1 \ldots$ & 101 & المجموع & \\
\hline \%тr, r & $1 \ldots$ & استاذ مساعد فأقل & \multirow[t]{3}{*}{ الرتبة الأكاديمية } \\
\hline$\%$ \% ч, & 01 & استاذ مشارك فأعلى & \\
\hline$\% 1 \ldots$ & 101 & المجموع & \\
\hline
\end{tabular}

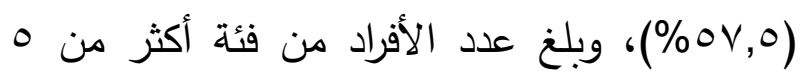

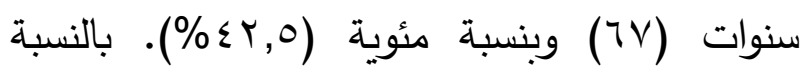
يظهر الجدول (1) بالنسبة لمتغير الخبرة: بلغ عدد لكتغير الرتبة الأكاديمية: بلغ عدد الأفراد من فئة

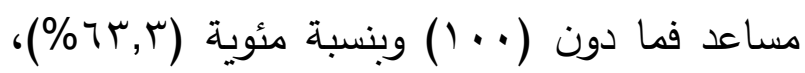
وبلغ عدد الأفراد من فئة مشارك فأعلى (ON) 
مناسبة وتعديل بعض الفقرات حسب المجال الذي

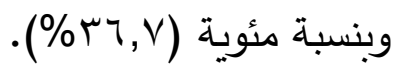
تنتمي اليه.

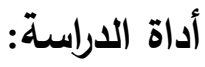

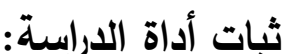
لأغراض إنفاذ الدراسة الحالية؛ فقد تم استخدام تم حساب ثبات أداة الدراسة بطريقة الاختبار وإعادة الاختبار (Test-R.test)، حيث تم توزيع الإستبانه الاستبانة أداة لجمع البيانات من أفراد عينة الدراسة،

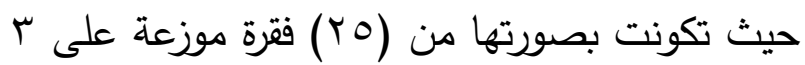
على عينة استطلاعية مكونة من عشرين عضوا من مجالات هي (البرامج الأكاديمية ج فقرات، و البحث أعضاء هيئة التدريس من غير أفراد عينة الدراسة

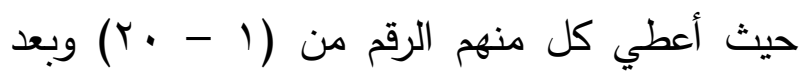
مضي أسبوعين تم إعادة تطبيق الأداة على العينة من العت نفسها مرة ثانية، حيث حصل الفرد على الرقم المتسلسل نفسه الذي حصل عليه في المرة الأولى، تهن، ومن ثم تم حساب معامل ارتباط بيرسون بين

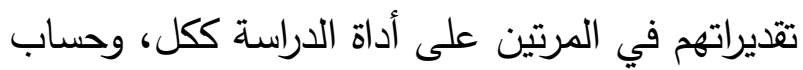
معامل الثبات بطريقة الاتساق الداخلي حسب معادئ لهادلة كرونباخ ألفا للدجالات والأداة ككل. والجدول (r) يبين هذه المعاملات.

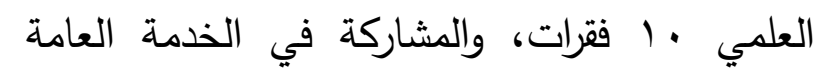

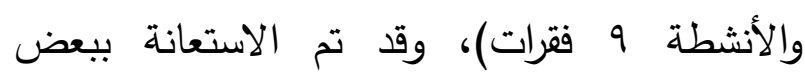
الدراسات السابقة في بناء الاستبانة مثل: دراسات

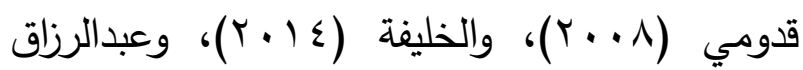

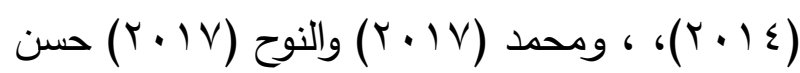
$\cdot(r \cdot I V)$ صدق أداة الدراسة: تم التحقق من صدق الاستبانة من خلال عرضها

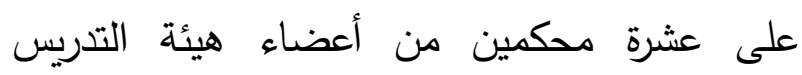

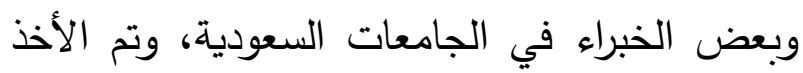
بتوجيهاتهم ومقترحاتهم من إضافة فقرات جديدة الجدول (ץ)معامل الاتساق الداخلي كرونباخ وثبات الإعادة للمجالات والأداة ككل

\begin{tabular}{|c|c|c|c|}
\hline ثبات الإعادة & الاتساق الداخلي & عدد الفقرات & المجال \\
\hline$\cdot, \wedge \varepsilon$ & $\cdot, \wedge)$ & 1 & البرامج الأكاديمية \\
\hline$\cdot, 10$ & • A & 1. & البحث العلمي \\
\hline$\cdot, \wedge 9$ & $\cdot, \wedge \mathrm{V}$ & 9 & المشاركة في الخذمات العامة والأنشطة له. \\
\hline r & •,95 & ro & الأداة ككل \\
\hline
\end{tabular}

يظهر من الجدول (r) إن معاملات الثبات بطريقة والأنشطة له " وأدناها لمجال " البرامج الأكاديمية "، اله

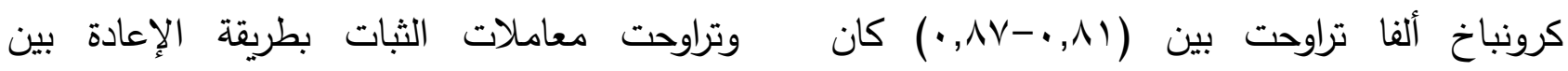

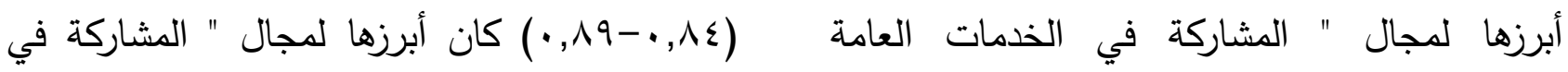


الخدمات العامة والأنشطة له" وأدناها لهجال " المعالجة الإحصائية:

تم حساب المتوسطات الحسابية والانحرافات المعيارية لمستوى الشراكة المجتمعية بين جامعة نجران ومنطقة نجران من وجهة نظر أعضاء هيئة التدريس في الجامعة تم حساب اختبار ت ت للعينات المستقلة للمجالات (Independent sample t.Test) والكلي للكشف عن وجود فروق ذات دلاله إحصائية

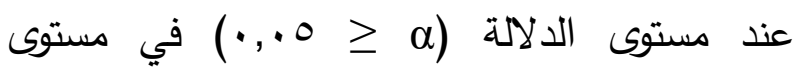
الثراكة المجتمعية بين جامعة نجران ومنطقة نجران من وجهة نظر أعضاء هيئة التدريس في الجامعة

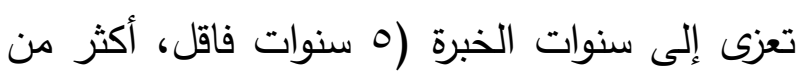
ه نوات).

تم حساب اختبار (ت) للعينات المستقلة للمجالات (Independent sample t.Test) والكلي للكشف عن وجود فروق ذات دلاله إحصائية

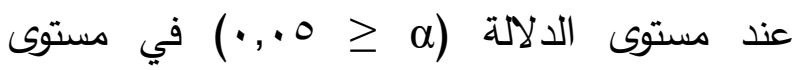
الشراكة المجتمعية بين جامعة نجران ومنطقة نجران من وجهة نظر أعضاء هيئة التدريس في الجامعة تعزى إلى الرتبة الأكاديمية (استاذ مساعد فأقل، استاذ مشارك فأعلى). عرض النتائج ومناقشتها: النتائج المتعلقة بالإجابة عن السؤال الأول: ما مستوى الثراكة المجتمعية بين جامعة نجران ومنطقة نجران من وجهة نظر أعضاء هيئة التدريس في الجامعة؟ البرامج الأكاديمية "، وجميعها معاملات ثبات مقبولة لأغراض تطبيق الدراسة. تصحيح المقياس: تكونت (الاستبانة) بصورتها النهائية التي تهدف الى قياس مستوى الثراكة المجتمعية بين جامعة نجران ومنطقة نجران من وجهة نظر أعضاء هيئة التدريس في الجامعة " وتكونت من (r) مجالات، المجال الأول (البرامج الأكاديمية) وتكون من (T) فقرة، المجال الثاني(البحث العلمي) وتكون من (·) (1) فقرات، المجال الثالث(المشاركة في الخدمات العامة والأنشطة) وتكون من (9) فقرات، حيث استخدم الباحث مقياس ليكرت للتدرج الخماسي بهدف قياس آراء أفراد عينة الدراسة، حيث تم التدريج للفقرات على النحو التالي: (كبيرة جدا) أعطي الدرجة رقم (0)، و(كبيرة) أعطي الدرجة رقم (ع)، و (متوسطة) أعطي الدرجة (r)، و(قليلة) أعطيت الدرجة (r) و(قليلة جدا) أعطي الدرجة رقم (1)، وذلك بوضع إشارة (ل) أمام الإجابة التي تعكس درجة موافقتهم، كما تم الاعتماد على التصنيف التالي للحكم على التهابه لهاته المتوسطات الحسابية كالتالي: متوسط حسابي (أقل من أو يساوي سب, ب) درجة تقدير منخفضة.

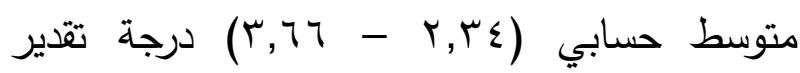
متوسطة. متوسط حسابي (TV, r - م 0) درجة تقدير مرتفعة. 
الجدول (r) :المتوسطات الحسابية والانحرافات المعيارية لمقياس " مستوى الثراكة المجتمعية بين جامعة نجران ومنطقة نجران

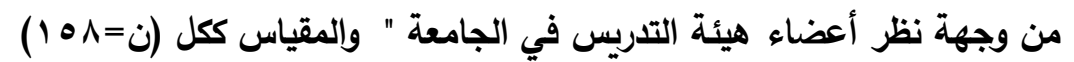

\begin{tabular}{|c|c|c|c|c|c|}
\hline الدرجة & الرتبة & الانحراف المعياري & الحستوسط & المجال & الرقم \\
\hline متوسطة & r & $\cdot, 0 Y$ & $r, \cdot v \tau$ & البرامج الأكاديمية & 1 \\
\hline متوسطة & r & $\cdot, 0 \leqslant$ & $r, \cdot v \wedge$ & البحث العلمي & r \\
\hline متوسطة & 1 & $\cdot, r v$ & $r, \cdot v q$ & المشاركة في الخدمات العامة والأنشطة له & r \\
\hline متوسطة & - & $\cdot \mu_{1}$ & $r, \cdot v \wedge$ & المقياس ككل & \\
\hline
\end{tabular}

يظهر من الجدول (r) أن المتوسطات الحسابية يمكن أن تحقق أهدافها وتبلغ طموحاتها. وإذا كان لمجالات مقياس " مستوى الشراكة المجتمعية بين الأمر كذلك، فلا أقل من أن ترد هذه الجامعات جامعة نجران ومنطقة نجران من وجهة نظر أعضاء بعض الجميل والعرفان لصاحب الفضل عليها، الذي

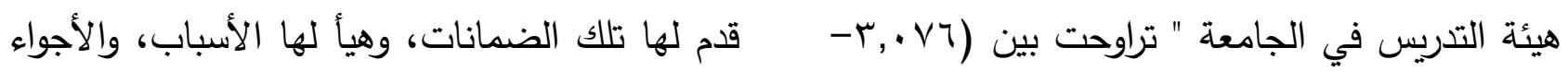

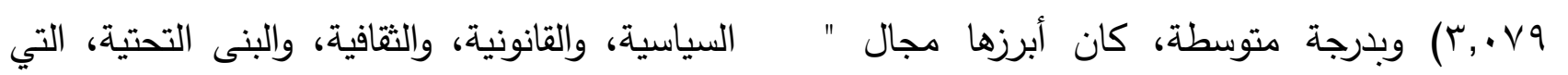
المشاركة في الخدمات العامة والأنشطة له " بمتوسط تسهل لها العمل، والإنتاج، والتوسع، والانطلاق من

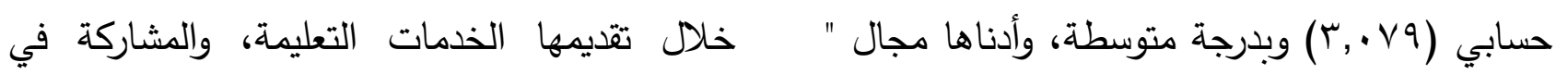

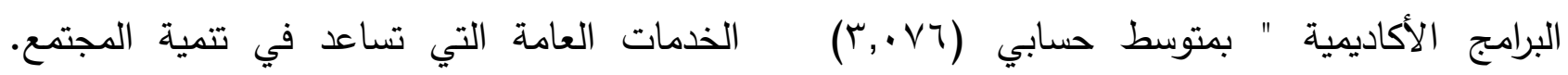
وبدرجة متوسطة، وبلغ المتوسط الحسابي للمقياس وأثارت دراسة (محمد، IV) إلى أن المتوسطات ككل " مستوى الشراكة المجتمعية بين جامعة نجران الحسابية لاستجابة أعضاء هيئة التدريس لدرجة ومنطقة نجران من وجهة نظر أعضاء هيئة التدريس تفعيل الشراكة المجتمعية لدى رؤساء الأقسام في

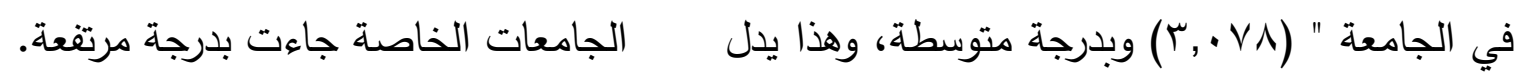
على وجود رعاية مجتمعية متواصلة، ولا تقوم هذه المجال الأول: البرامج الأكاديمية الرعاية بدون ضمانات تقدمها الجامعات للمجتمع لإجابة على هذا السؤال تم حساب المتوسطات الذي تعيش في أكنافه، فهو سبب وجودها وسبب والانحرافات المعيارية، وفي ما يلي عرض النتائج. بقائها ونموها وازدهارها، وبدونه لا يمكن أن تقوم، ولا 
الجدول ( ) المتوسطات الحسابية والانحرافات المعيارية لجميع فقرات المجال الأول" البرامج الأكاديمية "

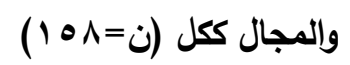

\begin{tabular}{|c|c|c|c|c|c|}
\hline الدرجة & الرتبة & الانحراف & الحستبط & الفقرة & الرقم \\
\hline متوسطة & 7 & $1, r 7$ & $r, \cdot r$ & يشترك المجتمع المحلي مع الجامعة في إعداد البرامج & 1 \\
\hline متوسطة & 0 & $1, r_{0}$ & $r, \cdot \varepsilon$ & يتعاون المجتمع المحلي مع الجامعة في تعزيز مبدأ & r \\
\hline متوسطة & 1 & 1,19 & $r, 1 \leq$ & والمعلومات المازمة التي ينبغي المحلي الجامعة في توفير المهارات & $r$ \\
\hline متوسطة & $\varepsilon$ & $1, r_{0}$ & $r, \cdot r$ & يشترك المجتمع المحلي مع الجامعة في وضع آليات القبول لتتلاءم مع احتياجات المجتمع المحلي. & $\varepsilon$ \\
\hline متوسطة & r & $1, r \mu$ & $r, \cdot v$ & يتعاون المجتمع المحلي والجامعة في إعداد وتطوير & 0 \\
\hline متوسطة & r & $1, r$ & r, & يتعاون المجتمع المحلي مع الجامعة في إعداد البرامج & 7 \\
\hline متوسطة & - &., $0 Y$ & $r, \cdot \Lambda$ & المجال ككل & \\
\hline
\end{tabular}

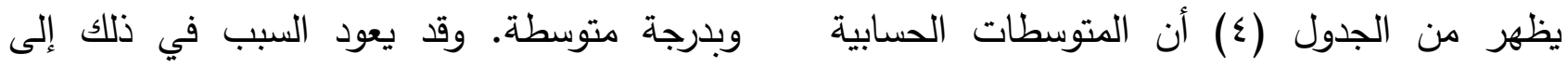

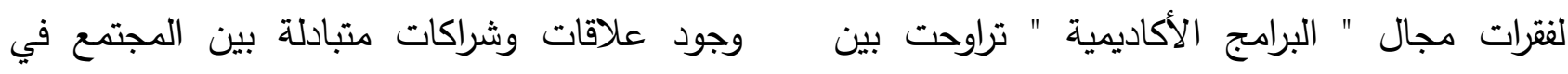

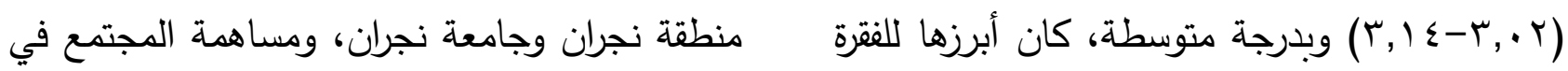

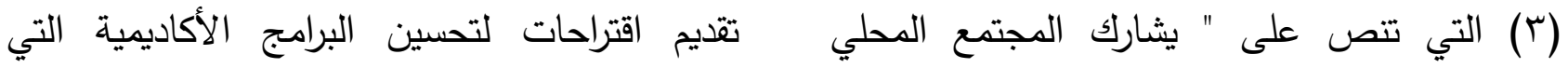
تقدمها الجامعة، ووجود تعاون بين المجتمع المحلي الجامعة في توفير المهارات والمعلومات اللازمة التي والجامعة في إعداد وتطوير وتدريب الكوادر البشرية ينبغي تضمينها في البرامج الأكاديمية" بمتوسط ولجات أكاديمياً ومهنياً، وتقديم الدعم والمساندة في تطوير وتلورير

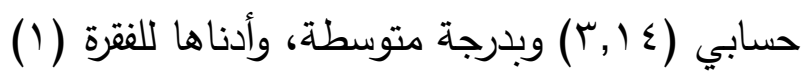
البرامج الأكاديمية وتدريب الطلاب ونقل الخبرات إلى ونى المجتمع لتتميته وتطويره. واتتقت هذه النتيجة مع ولئ

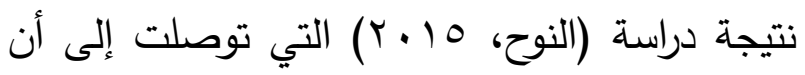
دور إدارة المدرسة في تفعيل العلاقة مع المجتمع لتحع

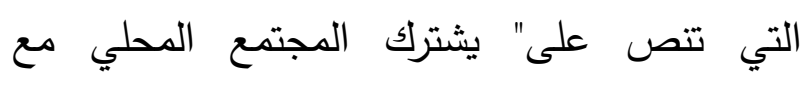
الجامعة في إعداد البرامج الأكاديمية " بمتوسط لتئي

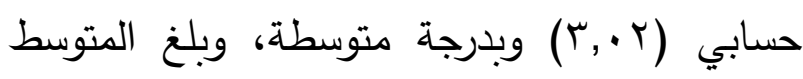

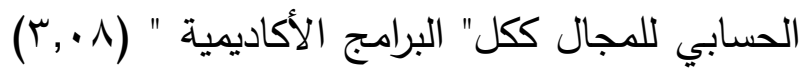


والانحرافات المعيارية، وفي ما يلي عرض النتائج.

المحلي جاء بدرجة متوسطة. المجال الثاني: البحث العلمي للإجابة عن هذا السؤال تم حساب المتوسطات

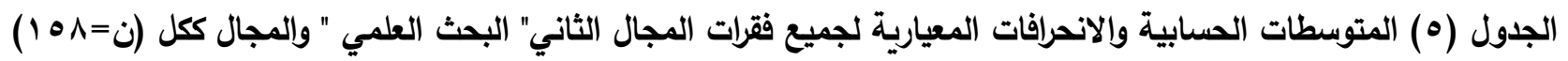

\begin{tabular}{|c|c|c|c|c|c|}
\hline الدرجة & الرتبة & 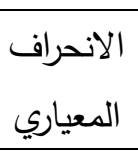 & الحتوسط & الفقرة & الرقم \\
\hline متوسطة & V & $1, r_{0}$ & $r, \cdot \varepsilon$ & 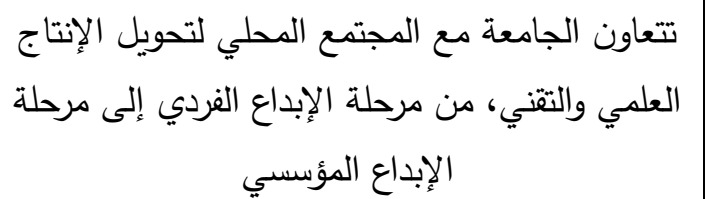 & 1 \\
\hline متوسطة & $r$ & 1,19 & $r, I r$ & تحرص الجامعة على نشر ثقافة أخلاقيات البحث & $r$ \\
\hline متوسطة & v & $1, r_{0}$ & $r, \cdot \varepsilon$ & تحرص الجامعة على إنشاء قاعدة معلومات مشتركة & $r$ \\
\hline متوسطة & $r$ & 1, ro & $r, 11$ & 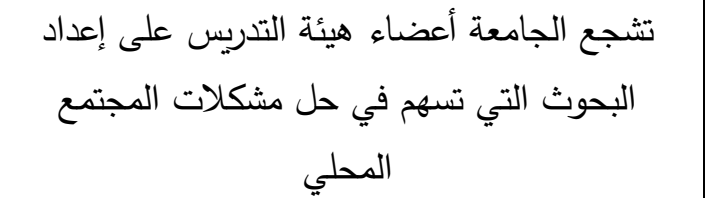 & $\varepsilon$ \\
\hline متوسطة & 1 & $1, r$. & $r, i r$ & من نتائج البحوث بما يخدم متطع المجتمع المحلي على الاستفادة & 0 \\
\hline متوسطة & 1. & I, ז & $r, \cdot r$ & توظف الجامعة البحث العلمي لتطوير نوعية وجودة & 7 \\
\hline متوسطة & 0 & $1, r 4$ & $r, \cdot v$ & تشجع الجامعة مع المحلي على إعداد البحوث التي & v \\
\hline متوسطة & $r$ & 1,11 & $r, 11$ & 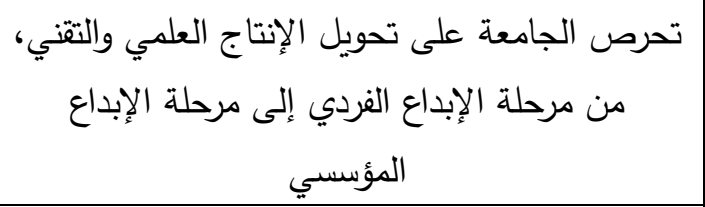 & $\wedge$ \\
\hline متوسطة & 1 & 1, ro & $r, .7$ & 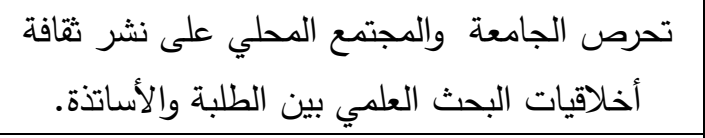 & 9 \\
\hline متوسطة & V & $1, r \varepsilon$ & $r, \cdot \varepsilon$ & تحرص الجامعة على إنشاء قاعدة معلومات مشتركة & 1. \\
\hline متوسطة & - & $\cdot, 0 \leqslant$ & $r, \cdot \Lambda$ & المجال ككل & \\
\hline
\end{tabular}



المختلفة بهدف تحديد مسارات بحثية واضحة يمكن أن تسهم في رقي المجتمع وتقدمه وتحقيق غايات

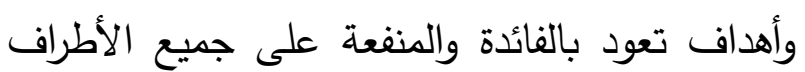

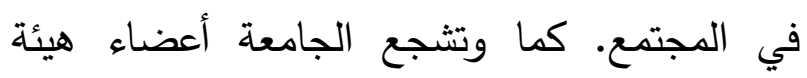
التدريس على إعداد البحوث التي تسهم في حل مشكلات المجتمع المحلي. المجال الثالث: المشاركة في الثئ الخدمات العامة والأنشطة له للإجابة عن هذا السؤال تم حساب المتوسطات والانحرافات المعيارية، وفي ما يلي عرض النتائج.
المنطقة، فالجامعة تحدد حاجات مؤسسات المجتمع

يظهر من الجدول (0) أن المتوسطات الحسابية

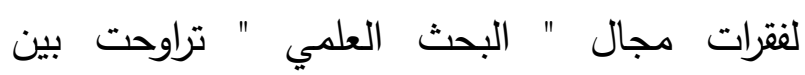

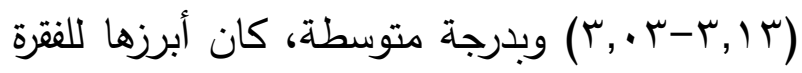

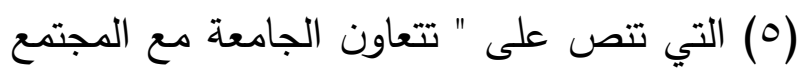

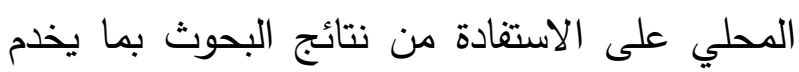

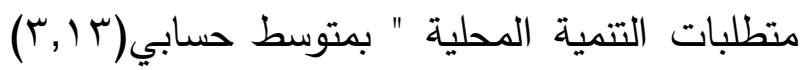

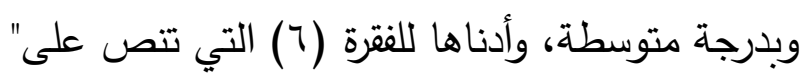
توظف الجامعة البحث العلمي لتطوير نوعية وجودة الحياة الاجتماعية " بمتوسط حسابي (r., (ץ) وبدرجة متوسطة، وبلغ المتوسط الحسابي للمجال ككل" البحث العلمي " (^, (r, وبدرجة متوسطة. ويرى الباحث أن البحث العلمي الذي تتفذه الجامعة

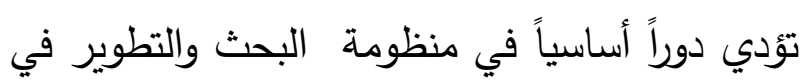
الجدول (†) المتوسطات الحسابية والانحرافات المعيارية لجميع فقرات المجال الثالث" المشاركة في الخدمات العامة والأنثطة له

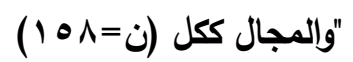

\begin{tabular}{|c|c|c|c|c|c|}
\hline 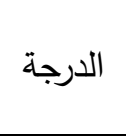 & 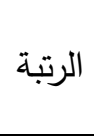 & الانحراف & الحتوسط & 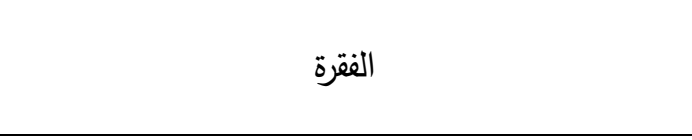 & 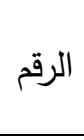 \\
\hline متوسطة & 1 & $1, r \cdot$ & $r, 17$ & تخصص الجامعة الفرص الترويحية للمجتمع المحلي & 1 \\
\hline متوسطة & 0 & $1, r 7$ & $r, \cdot r$ & 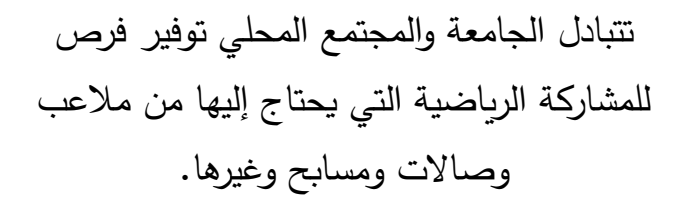 & r \\
\hline متوسطة & r & $1, r \cdot$ & r, Ir & تسهم الجامعة في التخفيف من مشكلة البطالة وذلك تشغيل أفراد المجتمع المحلي في المشاريع & r \\
\hline متوسطة & V & $1, r_{0}$ & $r, \cdot r$ & تسهم الجامعة والمجتمع بما لديها من مرافق عامة & $\varepsilon$ \\
\hline متوسطة & r & $1, r \varepsilon$ & $r, 11$ & تقدم الجامعة خدمات نوعية ومتخصصة لخدمة أفراد & ○ \\
\hline
\end{tabular}




\begin{tabular}{|c|c|c|c|c|c|}
\hline & & & & المجتمع. & \\
\hline متوسطة & $V$ & $1, Y 7$ & $r, \cdot r$ & تصدر الجامعة مجلات ونشرات وصحف يهتم & 7 \\
\hline متوسطة & V & $1, Y 7$ & $r, \cdot r$ & $\begin{array}{c}\text { تتعاون الجامعة مع مؤسسات المجتمع المحلي في المسرحيات والمنتديات الفكرية والثقافية } \\
\text { والأدبية. }\end{array}$ & V \\
\hline متوسطة & r & 1,11 & $r, 11$ & وتسهم الجامعة والمجتمع بما لديها من مرافق عامة في خدمة المستيدين من كلا الطرفين. & $\wedge$ \\
\hline متوسطة & 7 & 1, ro & $r, .0$ & تقدم الجامعة خدمات نوعية ومتخصصة لخدمة أفراد & 9 \\
\hline متوسطة & - & $\cdot, r V$ & $r, \cdot \Lambda$ & المجال ككل & \\
\hline
\end{tabular}

يظهر من الجدول (T) أن المتوسطات الحسابية والتكنولوجية المعاصرة، وتشغيل أفراد المجتمع لفقرات مجال " المشاركة في الخدمات العامة المحلي في المشاريع التي تقوم بها الجامعة، وقيادة والأنشطة له " تراوحت بين (T, (r-r,.,r) وجميعها المجتمع، ووضع الحلول الملائمة لمشكلاته، سواء بدرجة متوسطة، كان أبرزها للفترة (1) التي تتص التعليمية، أو الصحية، أو الصناعية ، أو البيئية، على " تخصص الجامعة الفرص الترويحية للمجتمع وخلافها من المشكلات التي يعاني منها المجتمع المحلي في المشاريع التي تقوم بها الجامعة " الحاضن لها، بالإضافة إلى أن الجامعة من خلال

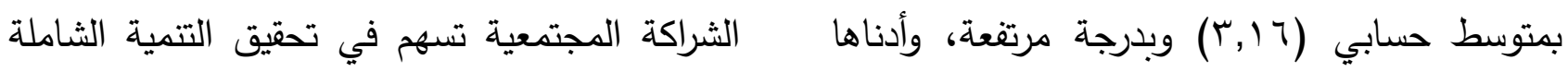
للفقرة (ع) التي تتص على" تسهم الجامعة، والمجتمع في المجالات المتعددة، وتهدف إلى تمكين أفراد بما لديها من مرافق عامة ومتخصصة في خدمة المجتمع، ومؤسساته، وهيئاته من تحقيق أقصى إفادة المستفيدين من كلا الطرفين" بمتوسط حسابي مدكنة من الخدمات المختلفة التي تقدمها الجامعة

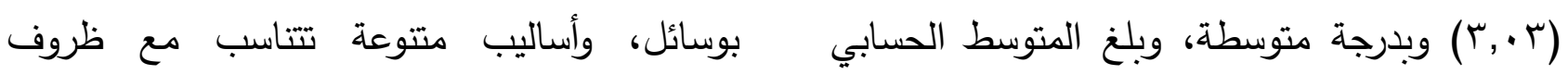
للمجال كل" المشاركة في الخدمات العامة المجتمع، وأفراده، وحاجاتهم الفعلية.

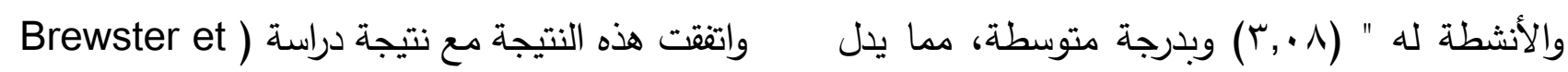
على خدمة الجامعة للمجتمع في زيادة المسؤولية al., 2016 ) التي بينت أن هناك تلبية لعديد من المجتمعية؛ من خلال إعداد العنصر البشري القادر أهداف الجامعة، والمجتمع في وقت واحد نتيجة على إحداث التمية المنشودة من خلال تبني إعداد الثراكة المجتمعية. وعلى وجه التحديد، فإنها تركز القوى العاملة القادرة على مواجهة التغييرات العلمية، على احتياجات المجتمع من خلال معالجة قضية 
اجتماعية متفق عليها بشكل متبادل، وتبني وتعزز إلى الخبرة؟

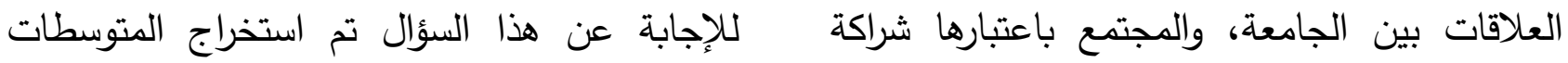
الحسابية، والانحرافات المعيارية مستوى الشراكة متساوية. النتائج المتعلقة بالإجابة عن السؤال الثاني: هل المجتمعية بين جامعة نجران، ومنطقة نجران، من الهن

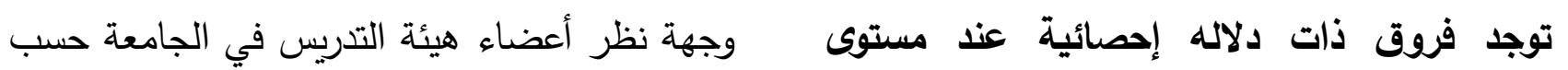
الالالة ( المجتمعية بين جامعة نجران ومنطقة نجران من المتوسطات الحسابية تم استخدام اختبار "ت"،

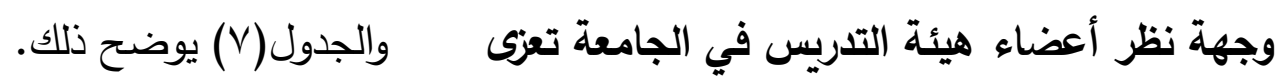

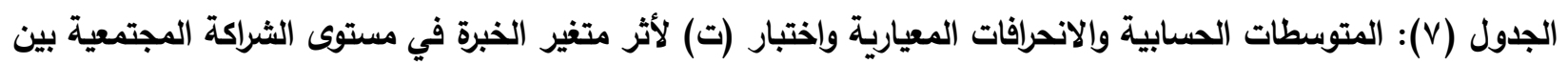

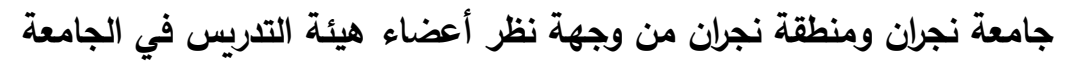

\begin{tabular}{|c|c|c|c|c|c|c|c|}
\hline \multirow{2}{*}{ الإحصائية } & \multirow{2}{*}{ قيمة ت } & \multirow{2}{*}{ الحرية } & \multicolumn{2}{|c|}{$\begin{array}{c}\text { أكثر من ه سنوات } \\
\text { (TV) }\end{array}$} & \multicolumn{2}{|c|}{$\begin{array}{c}\text { سنوات فاقل } \\
\text { (9 (9) }\end{array}$} & \multirow{2}{*}{ المجالات } \\
\hline & & & الانحراف & الحسابي & الانحراف & الحسابي & \\
\hline$\cdot, Y \backslash)$ & $1, v \varepsilon$ & 107 & $\cdot, \leqslant \wedge$ & $r, 99$ & $\cdot, 00$ & $r, 1 \varepsilon$ & البرامج الأكاديمية \\
\hline 更 & $-\varepsilon, 99$ & 107 & $\cdot, \leqslant 9$ & $r, 1$. & $\cdot, 01$ & $r, .7$ & البحث العلمي \\
\hline$\cdot, T V Y$ & $\cdot, Y 17$ & 107 & דז, • & $r, \cdot v$ & , rی & $r, \cdot \wedge$ & العامة والأنشطة لهي الخدمات \\
\hline . rVV & $\cdot, \leq \leqslant \leq$ & 107 & $\cdot, r q$ & $r, \cdot V$ & ש & $r, . q$ & الأداة ككل \\
\hline
\end{tabular}
يتبين من الجدول (V)(عدم وجود فروق ذات دلالة إحدى الأدوات التي يمكن من خلالها النهوض

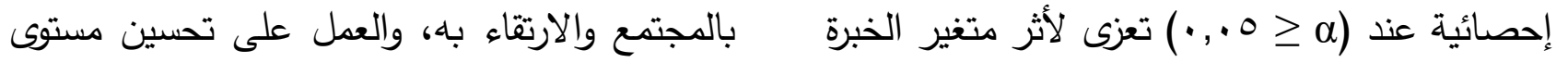
في مستوى الشراكة المجتمعية بين جامعة نجران حياة المواطنين اجتماعيا واقتصاديا وذلك من خلال ومنطقة نجران من وجهة نظر أعضاء هيئة التدريس إسهام أبناء المجتمع تطوعا في جهود التنمية سواء

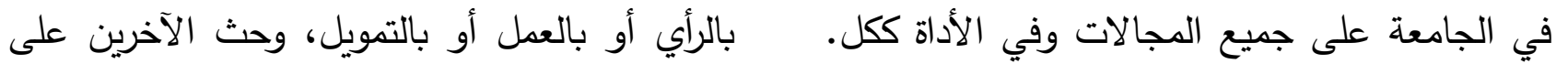

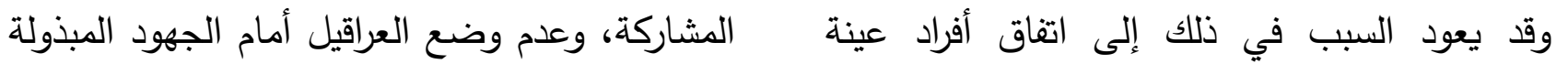
الدراسة على أهمية الشراكة المجتمعية التي تعد من جانب قيادات المجتمع وغير ذلك من الأمور 
التي تؤدى إلى تتمية المجتمع وتحقيق أهدافه. كما المجتمعية بين جامعة نجران ومنطقة نجران من

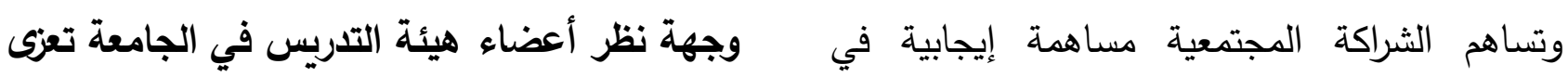

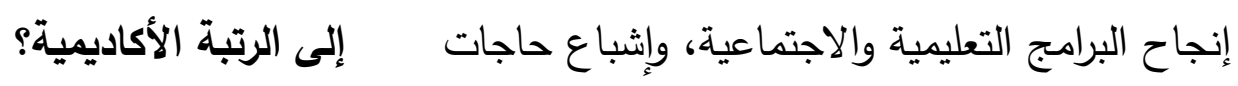

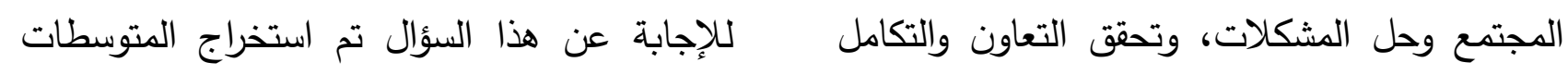

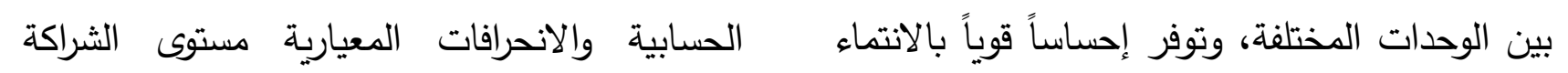

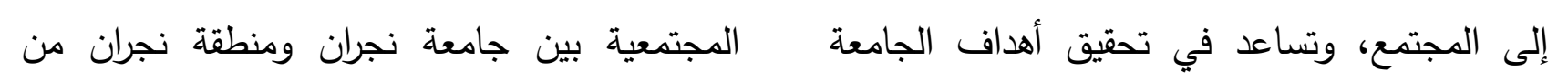

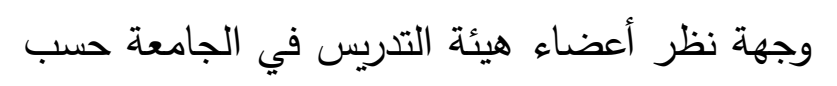
والمجتمع معاً.

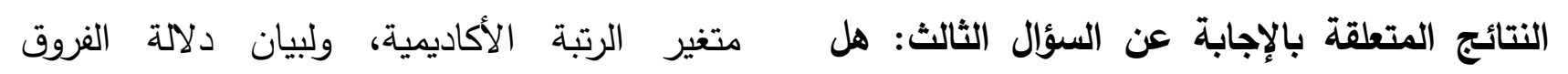
توجد فروق ذات دلاله إحصائية عند مستوى الإحصائية بين المتوسطات الحسابية تم استخدام الالالة (

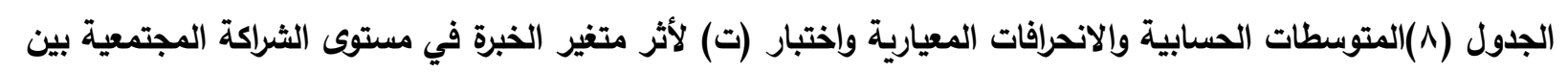

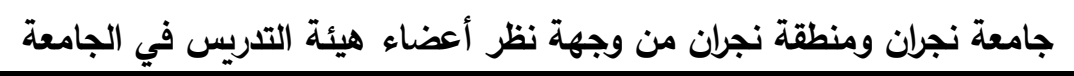

\begin{tabular}{|c|c|c|c|c|c|c|c|}
\hline \multirow{2}{*}{ الإحصائية } & \multirow{2}{*}{ قيمة ت } & \multirow{2}{*}{ الحرية } & \multicolumn{2}{|c|}{ أستاذ مشارك فأعلى (o^ ) } & \multicolumn{2}{|c|}{ 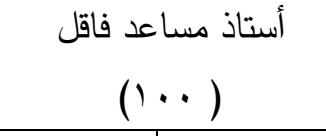 } & \multirow{2}{*}{ المجالات } \\
\hline & & & الانحراف & المتوسط & الانحراف & المتوسط & \\
\hline$\cdot, \wedge \vee$. & $\cdot, \vee>1)$ & 107 & $\cdot, 01 Y$ & $r, r_{0}$ & $\cdot$, OYA & $r, 1$. & البرامج الأكاديمية \\
\hline س & $\cdot, T \cdot r-$ & 107 & $\cdot, 009$ & $r, 11 r$ &., 010 & $r, \cdot \tau$ & البحث العلمي \\
\hline$\cdot, 10$ & $1, \cdot \leq r$ & 107 & $\cdot, \varepsilon \cdot \varepsilon$ & $r, \cdot r \wedge$ & $\cdot, r \circ r$ & $r, 1 \cdot$ & العشاركة في الخدمات \\
\hline$\cdot, 109$ & ( & 107 & •, rrA & $r, \cdot T V$ & $\cdot, Y 90$ & $r, \cdot \Lambda$ & الأداة ككل \\
\hline
\end{tabular}

شراكة مجتمعية بين الجامعة ومنطقة نجران بغض النظر عن رتبهم الأكاديمية ولاقتناعهم بأن الشراكة المجتمعية من المقومات الرئيسة لتطوير القطاعات

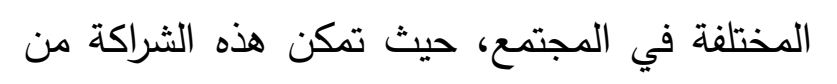

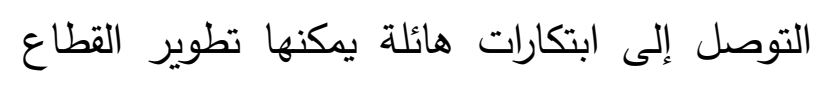

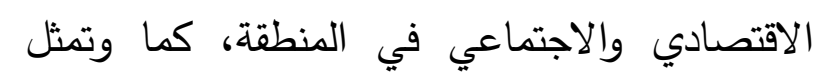

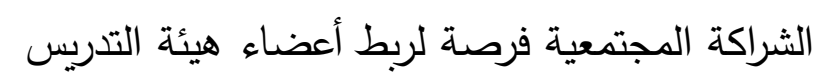

يتبين من الجدول (^)عدم وجود فروق ذات دلالة

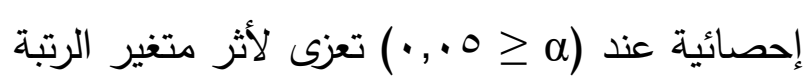
الأكاديمية في مستوى الشراكة المجتمعية بين جامعة نجران ومنطقة نجران من وجهة نظر أعضاء هيئة التريس في الجامعة على جميع المجالات وفي الأداة ككل، وهذا يدل على اهتمام جميع أفراد عينة

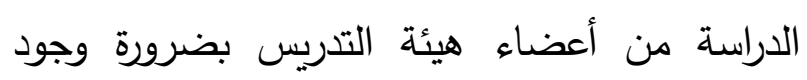


الوقاية من الجريمة، جامعة نايف العربية للعلوم الأمنية، كلية العدالة الجنائية، السعودية.

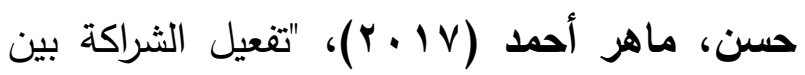

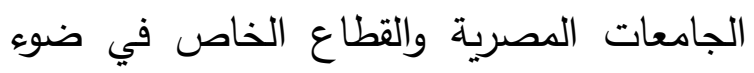
خبرات وتجارب بعض الدول المتقدمة"، المجلة

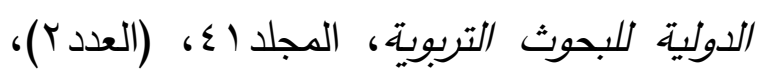

$$
\text { . } r 9 \leq-r \leq \text {. }
$$

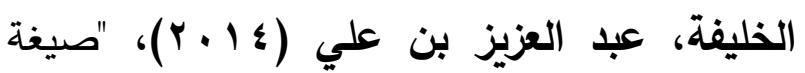

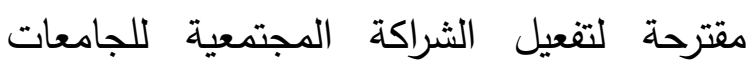

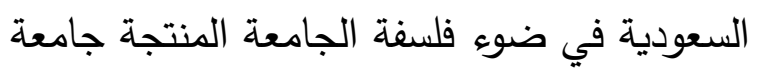
الإمام محمد بن سعود الإسلامية أنموذجا"، مجلة رسالة التربية وعلم النفس(جامعة الملك سعود)،

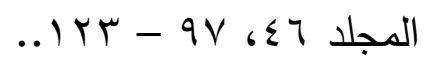

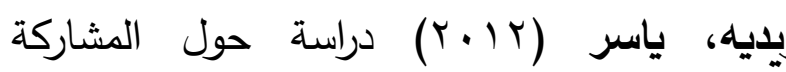
المجتمعية في قطاع غزة، دراسة حالة بلدية المغازي، رسالة ماجستير غير منشورة، الجامعة الإسلامية، غزة، فلسطين.

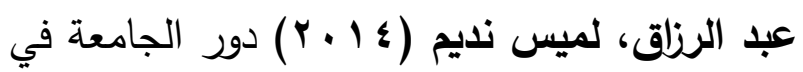
تتمية العلاقات الاجتماعية والمسؤولية الوطنية، دراسة ميدانية في جامعتي دمشق وتشرين، رسالة ماجستير غير منشورة، جامعة دمشق، سوريا،.

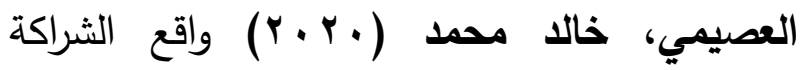
المجتمعية و درجة ممارسة مجالاتها في جامعة الطائف من وجهة نظر أعضاء هيئة التدريس.

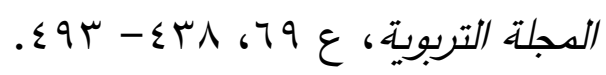

بالجامعة بمؤسسات المجتمع، وقضاياه، ومشكلاته،

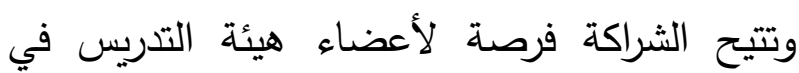
تحسين المستوى الفردي، والعلمي.

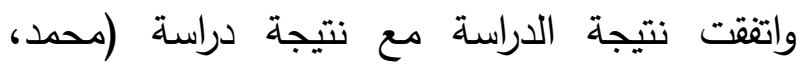

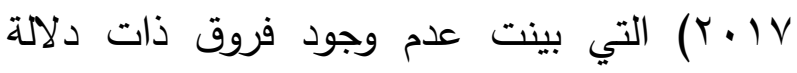
إحصائية في درجة تفعيل الشراكة المجتمعية لدى لدى لرون رؤساء الأقسام في الجامعات الخاصة من وجهة نظر أعضاء هيئة التدريس تبعاً لمتغير الرتبة

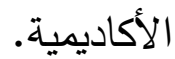

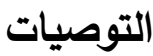

بناءاً على النتاج التي توصلت لها الدراسة يوصي

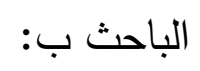

- قيام وزارة التعليم العالي على وضع أنظمة تساعد

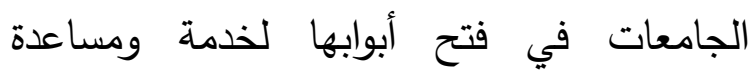
المجتمع والتشارك معه.

- العمل على إثراء البحث العلمي والأنشطة الإبداعية والابتكارية، وتعزيز البرامج الأكاديمية

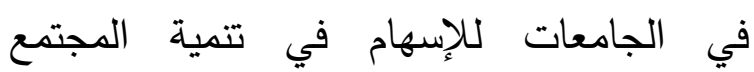
وتطويره. - إجراء المزيد من الدراسات التي تبحث في الثراكة المجتمعية بين الجامعات والمجتمع المحلي، وبين الجامعات والمؤسسات المجتمعية المختلفة.

$$
\text { المراجع }
$$

أولاً: المراجع العربية:

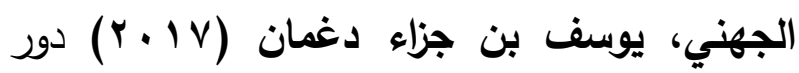
إدارات الشراكة المجتمعية بإمارات المناطق في دعمان 
رسالة ماجستير غير منشورة، جامعة الشرق الأوسط، عمان، الأردن.

المزين، سليمان؛ وصبيح، لينا (10 • ب) معوقات تفعيل الشراكة المجتمعية في الجامعات الفلسطينية بمحافظات غزة، مجلة جامعة النجاح للغبحاث، و

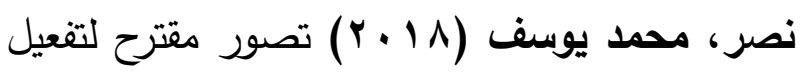

الشراكة المجتمعية بجامعة تبوك في ضوء الرؤية

الوطنية للمملكة،ب.بام، مجلة كلية التربية، $. V \leq \varepsilon-790 \cdot(1 \vee \Lambda) \mu v$

النوح، عبد العزيز بن سالم (10 • r) دور إدارة

المدرسة في تفعيل الشراكة بين المدرسة وبين

المجتمع المحلي، دراسة ميدانية، مجلة العلوم

$$
\text { التربوية، العددس، هبr - ثانياً: المراجع الأجنبية: }
$$

Baker, Elizabeth A.,Wilkerson, Risa and Bernan, Laura K. (2012)," Identifying the role of community partnerships in creating change to support active living", Am J Prev Med. Vol. 43,(5 Suppl 4): S290-S299. doi: 10.1016/j.amepre.2012.07.003.

Brewster, Ann B. , Pisani, Paul, Ramseyer, Max , and Wise, Jack (2016), "Building a university-community partnership to promote high school graduation and beyond: An innovative undergraduate team approach", Journal of Applied Research in Higher Education, Vol. 8 Issue: 1, pp.4458, https://doi.org/10.1108/JARHE-10-20140093

Buys, Nicholas and Bursnall, Samantha (2007), "Establishing university-community partnerships: Processes and benefits", Journal of Higher Education Policy and Management. Volume 29, Issue 1. Pages 7386
قدومي، منال عبد المعطي صالح (^ . . ب) دور

المشاركة المجتمعية في تتمية وتطوير المجتمع

المحلي، حالة دراسية للجان الأحياء السكنية في

مدينة نابلس، رسالة ماجستير غير منشورة، جامعة النجاح الوطنية، فلسطين.

القرشي، محسن بن عليان بن حمود (11) المشاركة المجتمعية المطلوبة لتطوير أداء

المدارس الثانوية الحكومية، دراسة ميدانية على

المدارس الثانوية الحكومية بمحافظة الطائف،

رسالة ماجستير غير منشورة، جامعة أم القرى،

السعودية.

محمد، زينب سمير (YV) تفعيل الشراكة

المجتمعية لدى رؤساء الأقسام في الجامعات

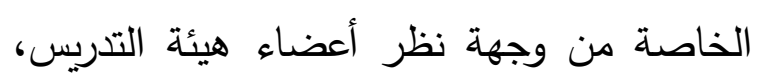

Clover, Darlene E. and McGregor, Catherine (2008), Community-University Partnerships: Connecting for Change. University of Victoria,Victoria,Canada.ttps://depts.washingt on.edu/ccph/pdf_files/CUexpo_proceedings.p df

Curwood, Susan E. , Munger, Felix, Mitchell, Terry, Mackeigan, Mary, and Farrar, Ashley (2011), "Building Effective Community-University Partnerships: Are Universities Truly Ready?", Michigan Journal of Community Service Learning. pp. 15-26. https://files.eric.ed.gov/fulltext/EJ967603.pdf.

Davis, H., \& Meltzer, L. (2007), Working with parents in partnership (Early Support Distance Learning Text). Department for Education and Skills (UK), Sure Start, Department of Health (UK). Retrieved from:http://dera.ioe.ac.uk/15598/1/working_w ith_parents_in_partnership.pdf.

Level of Community Partnership Between Najran University and Najran Region from the Faculty 


\title{
Level of Community Partnership Between Najran University and Najran Region from the Perspective of Faculty Members
}

\author{
Fuad Shabib Khassawneh \\ Assistant professor of Educational Administration, \\ Deanship of Community Service and Continuing \\ Education, Najran University
}

\begin{abstract}
Najran University and Najran region from the faculty members' point of view of the university, being based on descriptive approach. The study sample consisted of (158) faculty members. The findings pointed out that the level of community partnership between Najran University and Najran region from the faculty members' point of view at the university was at "(3.078) to the medium degree. Also, the findings pointed out that there were no statistically significant differences due to the effect of experience and the academic variables at the level of community partnership between Najran University and Najran region from their point of view on all domains and the instrument as a whole. The study ended by some recommendations .

Keywords: community partnership, Najran region, Najran University, Faculty members. Saudi Arabia.
\end{abstract}

